\title{
Breast Cancer in Low and Middle Income Countries: How Can Guidelines Best Be Disseminated and Implemented?
}

\author{
Benjamin O. Anderson Vivien D. Tsu \\ University of Washington, Seattle, WA, USA
}

Breast cancer is the most common cancer of women, comprising $23 \%$ of all female cancers around the globe, with an estimated 1.15 million cases diagnosed in 2002 [1]. It is also the leading cause of cancer mortality among women worldwide, with about 411,000 deaths each year. Approximately 4.4 million women with breast cancer diagnosed in the last 5 years are currently alive [2]. There is marked geographical variation in incidence rates, being highest in the developed world and lowest in the developing countries of Asia and Africa. The agestandardized incidence in North America is the highest, at 99.4 per 100,000 while the lowest is in central Africa where it is 16.5 per 100,000 [3].

In most low and middle income countries (LMCs), incidence rates are increasing at a more rapid rate than in areas where incidence rates are already high. Global breast cancer incidence rates have increased by about $0.5 \%$ annually since 1990 ; by contrast, cancer registries in China are recording annual increases in incidence of 3-4\% [1]. In the urban areas of India, cervical cancer had the highest incidence among female cancers 15 years ago, but has now been overtaken by breast cancer as the most commonly diagnosed cancer among women [4]. Despite the younger age structure of most developing countries, breast cancer already accounts for about $45 \%$ of the incident cases and $54 \%$ of the annual deaths [5]. Even assuming conservatively no change in underlying age-specific rates, there could be a nearly $50 \%$ increase in global incidence and mortality between 2002 and 2020 due to demographic change alone, with disproportionate shares of that increase occurring in the developing world - with increases of $55 \%$ in incidence and $58 \%$ in mortality in less than 20 years [5]. This probably represents an underestimate of reality since the few data available from LMCs reveal increases in breast cancer age-specific incidence and mortality rates, especially in recent birth cohorts. This is especially true among urban women and is probably due at least in part to the adoption of Western lifestyles [2,6].

\section{Breast Cancer Detection, Treatment and Outcome}

Improvements in survival in the industrial world seen in recent decades have been attributed to early detection by screening, and to timely and effective treatment guided by extensive and rigorous clinical trials [7]. Randomized trials of clinical breast examination (CBE) and screening mammography initiated in the 1970s showed that early cancer detection within a given population leads to down-staging of disease and improvement in breast cancer survival. Randomized trials of breast conserving therapy vs. mastectomy demonstrated that smaller, less morbid surgical procedures could achieve equivalent outcome, making local-regional treatment more acceptable to women diagnosed with disease. Randomized trials of systemic therapies for breast cancer proved that endocrine therapy for estrogenreceptor positive $(\mathrm{ER}+)$ cancers and cytotoxic chemotherapy for ER-cancers improves survival and durable long-term cure among lymph node negative, lymph node positive, and even locally advanced breast cancers [8]. As a result, breast cancer mortality, which had been relatively unchanged from the 1930s through the $1980 \mathrm{~s}$, has been dropping by $1.4-3.1 \%$ per year between 1990 and 2003 in the United States [9]. Notably, minority women in the US are more likely to present with advanced stage disease and have higher mortality rates than do white women, although white and black women presenting with similar stage disease and receiving similar treatment have similar outcomes. These findings suggest that differences in stage at presentation and treatment should represent the primary targets of research and interventions designed to reduce disparities in cancer outcomes among women [10].

Prognosis from breast cancer is rather good in well-resourced settings. For example, women diagnosed with breast cancer between 1990 and 1992 and reported in the population-based case series from the Surveillance, Epidemiology, and End Results (SEER) program (13,172 women) had an 89\% 5-year

\begin{tabular}{ll}
\hline KARGER & @ 2008 S. Karger GmbH, Freiburg \\
Fax +497614520714 & Accessible online at: \\
$\begin{array}{l}\text { E-mail Information@Karger.de } \\
\text { www.karger.com }\end{array}$ & www.karger.com/brc
\end{tabular}

\section{KARGER}

E-mail Informa
www.karger.com
Benjamin O. Anderson, MD

Department of Surgery, University of Washington

Box 356410, 1959 NE Pacific St., Seattle, WA 98195, USA

Tel. +1 206 543-6352, Fax -8136

E-mail banderso@u.washington.edu 
survival rate [11]. European women during the same period had a lower but still substantial 79\% 5-year survival rate, as reported in the EUROCARE study (4,478 women) of 17 population-based registries in 6 European countries [11]. By contrast, age-adjusted survival rates for breast cancer in developing regions average $57 \%$ and are as low as $46 \%$ in India and $32 \%$ in sub-Saharan Africa [1].

In LMCs, worsened cancer survival is largely due to late stage presentation, which leads to particularly poor outcome when coupled with limited diagnosis and treatment capacity [12]. Of the over 75,000 new cases presenting for treatment each year in India, between 50 and $70 \%$ have locally advanced breast cancer at diagnosis [13]. By comparison, 38\% of European and $30 \%$ of American breast cancer cases were reported to be locally advanced at diagnosis (T2-3N0 or T4Nx) in the EUROCARE study and SEER cancer registry between 1990-1992 [11]. Compounding the problem of late diagnosis, breast cancer case fatality rates are high, because LMCs typically lack major components of health care infrastructure and resources necessary to implement improved methods for early detection, diagnosis and treatment of breast cancer [14, 15]. Although lowresource countries have not identified cancer as a priority health care issue because infectious diseases are a predominant public health problem, cancer care will become an important health problem over the next decades as the control of communicable diseases improves and life expectancy rises [2].

\section{Guideline Development}

Evidence-based guidelines outlining optimal approaches to breast cancer detection, diagnosis, and treatment have been developed and disseminated in several high resource countries $[16,17]$. Even in some developing countries, there have been attempts to develop clinical practice guidelines for the treatment of breast cancer based on the resources available [18]. Most guidelines define optimal practice, which have limited utility in developing countries where resources are poor. Optimal practice guidelines may be inappropriate to apply in LMCs for numerous reasons, including personal resources, infrastructure, drugs and cultural barriers. Hence, there is a need to develop clinical practice guidelines oriented towards countries with limited financial resources [19].

Established in 2002 and co-sponsored by the Fred Hutchinson Cancer Research Center and Susan G. Komen for the Cure, the Breast Health Global Initiative (BHGI) created an international health alliance to develop evidence-based guidelines for LMCs to improve breast health outcomes. The BHGI collaborated with 12 national and international health organizations, cancer societies, and non-governmental organizations to develop evidence-based guidelines for breast cancer program development in resource-poor countries [20]. The now completed BHGI resource-sensitive guidelines define comprehensive evidence-based pathways for coordinated step-by-step quality improvement in breast cancer early detection, diagnosis and treatment. The BHGI guidelines can be used as the basis for strategic plans for programmatic improvement following approaches that consider projected cost and cost-effectiveness in their development. This stepwise, systematic approach to health-care improvement applies a tiered system of resource allotment defined using four levels - basic, limited, enhanced, and maximal - based on the contribution of each resource toward improving clinical outcomes. Evidence-based recommendations are summarized in tables that prioritize critical resources to facilitate programmatic improvement in breast cancer early detection, diagnosis and treatment within established but resource-limited health care systems. Because the BHGI guidelines are comprehensive in nature and systematically address care from initial disease identification to completion of therapy, they can be expected to improve breast cancer outcomes once they are successfully disseminated and implemented within targeted LMCs. In their 2007 report, Cancer Control Opportunities in Low- and Middle-Income Countries, the Institute of Medicine (IOM) provides a detailed summary of BHGI methodology, which the editors identify as a model approach for developing resource-sensitive guidelines that could be applied to other cancers or chronic diseases for which effective treatments are available [21]. A systematic evaluation of these outcomes awaits full implementation of the guidelines in a range of LMCs.

\section{Guideline Dissemination and Implementation}

The dominant paradigm even now in the medical community is that good research and publication should be sufficient to ensure the translation of scientific findings into general practice [22]. Unfortunately, a landmark Institute of Medicine (IOM) report from 2001 clearly identified the failure of much scientific innovation to be translated into practice [23, 24]. More recently, Rubenstein and Pugh separated the IOM's second translational block - clinical research to practice - into two parts: i) clinical research to guidelines and ii) guidelines to practice [25]. Dissemination and implementation researchers maintain that the process is complex and have begun to identify factors and processes critical to the adoption of new technologies and practices [26]. While there has been some work already on assessing readiness for change, it has usually focused on just one component, such as providers or health units, or has focused on intention without considering self-efficacy or environment. As a conclusion in her extensive review of the implementation literature, Greenhalgh notes the need for more research on system readiness for innovation and for more studies evaluating implementation of specific interventions [27].

Very little research on guideline implementation has been done in LMCs. It is necessary to see whether the basic frameworks and instruments being described in high-income coun- 
tries apply in these very different environments and what adaptation is needed to make them both valid and feasible. A systematic program of research to develop appropriate readiness assessment instruments and identify effective implementation strategies is now needed in a variety of LMCs. As we move forward to support the adoption, implementation, and maintenance of the new evidence-based principles embodied in the BHGI guidelines, it is critical that careful evaluation be incorporated in the efforts, to ensure that lessons about effectiveness and efficiency are captured. It is precisely because resources are more scarce in these countries, that it is even more imperative that LMCs adopt effective practices as quickly as possible, and that implementation approaches are designed with limited resources in mind [22].

\section{References}

1 Parkin DM, Bray F, Ferlay J, Pisani P: Global cancer statistics, 2002. CA Cancer J Clin 2005;55(2):74-108.

2 Parkin DM, Fernandez LM: Use of statistics to assess the global burden of breast cancer. Breast J 2006;12 Suppl 1:S70-80.

3 Parkin DM, Whelan SI, Ferlay J, Storm H: Cancer Incidence in Five Continents, Vol I-VIII. IARC CancerBase no 6., Lyon, IARC Press, 2005.

$\checkmark 4$ Pal SK, Mittal B: Improving cancer care in India: prospects and challenges. Asian Pac J Cancer Prev 2004;5(2):226-8.

5 Ferlay J, Bray F, Pisani P, Parkin DM: GLOBOCAN 2002: Cancer Incidence, Mortality and Prevalence Worldwide. IARC CancerBase No. 5. version 2.0, Lyon, IARCPress, 2004.

6 Porter P: 'Westernizing' women's risks? Breast cancer in lower-income countries. N Engl J Med 2008; 358(3):213-6.

7 Weir HK, Thun MJ, Hankey BF, Ries LA, Howe HL, Wingo PA, et al.: Annual report to the nation on the status of cancer, 1975-2000, featuring the uses of surveillance data for cancer prevention and control. J Natl Cancer Inst 2003;95(17):1276-99.

$\checkmark$ Clarke M: Meta-analyses of adjuvant therapies for women with early breast cancer: the Early Breast Cancer Trialists' Collaborative Group overview. Ann Oncol 2006;17 Suppl 10:x59-62.

9 Jemal A, Siegel R, Ward E, Murray T, Xu J, Thun MJ: Cancer statistics, 2007. CA Cancer J Clin 2007; 57(1):43-66.

10 Bach PB, Schrag D, Brawley OW, Galaznik A, Yakren S, Begg CB: Survival of blacks and whites after a cancer diagnosis. Jama 2002;287(16):2106-13.
11 Sant M, Allemani C, Berrino F, Coleman MP, Aareleid T, Chaplain G, et al.: Breast carcinoma survival in Europe and the United States. Cancer 2004; 100(4):715-22.

12 Hisham AN, Yip CH: Spectrum of breast cancer in Malaysian women: overview. World J Surg 2003; 27(8):921-3.

13 Chopra R: The Indian scene. J Clin Oncol 2001; 19(18 Suppl):106S-111S.

14 Greenlee RT, Murray T, Bolden S, Wingo PA: Cancer statistics, 2000. CA Cancer J Clin 2000; 50(1):7-33

15 Zotov V, Shyyan R: Introduction of breast cancer screening in Chernihiv Oblast in the Ukraine: report of a PATH Breast Cancer Assistance Program experience. Breast J 2003;9 Suppl 2:S75-80.

16 Goldhirsch A, Glick JH, Gelber RD, Coates AS, Thurlimann B, Senn HJ: Meeting highlights: international expert consensus on the primary therapy of early breast cancer 2005. Ann Oncol 2005;16(10): 1569-83.

17 Carlson RW, Anderson BO, Burstein HJ, Cox CE, Edge SB, Farrar WB, et al. Breast cancer. J Natl Compr Canc Netw 2005;3(3):238-89.

18 Management of breast cancer. In: Clinical Practice Guidelines, Ministry of Health Malaysia: Academy of Medicine Malaysia; 2002.

19 Executive summary of the national cancer control programmes: policies and managerial guidelines. Geneva, World Health Organization, 2002.
20 Anderson BO, Shyyan R, Eniu A, Smith RA, Yip $\mathrm{CH}$, Bese NS, et al.: Breast cancer in limitedresource countries: an overview of the Breast Health Global Initiative 2005 guidelines. Breast J 2006;12 Suppl 1:S3-15.

21 Sloan FA, Gelband H (eds): Cancer Control Opportunities in Low- and Middle-Income Countries (summary). Washington, D.C., The National Academies Press, 2007, pp 1-16.

22 McCannon CJ, Berwick DM, Massoud MR: The science of large-scale change in global health. Jama 2007;298(16):1937-9.

23 Crossing the Quality Chasm: A New Health System for the 21st Century. Institute of Medicine. Washington, National Academy Press, 2001.

24 No authors listed: IOM committee calls for complete revamping of health care system to achieve better quality. Qual Lett Healthc Lead 2001;13(3): 14-5.

25 Rubenstein LV, Pugh J: Strategies for promoting organizational and practice change by advancing implementation research. J Gen Intern Med 2006;21 Suppl 2:S58-64.

26 Grimshaw J, Eccles M, Thomas R, MacLennan G, Ramsay C, Fraser C, et al.: Toward evidence-based quality improvement. Evidence (and its limitations) of the effectiveness of guideline dissemination and implementation strategies 1966-1998. J Gen Intern Med 2006;21 Suppl 2:S14-20.

27 Greenhalgh T, Robert G, Macfarlane F, Bate P, Kyriakidou O: Diffusion of innovations in service organizations: systematic review and recommendations. Milbank Q 2004;82(4):581-629. 